\title{
Possibilidades de uso da teoria das representações sociais para os estudos pessoa-ambiente
}

\author{
Gislei Mocelin Polli \\ Ariane Kuhnen \\ Universidade Federal de Santa Catarina
}

\begin{abstract}
Resumo
Os problemas ambientais gerados pelo comportamento humano são antigos, mas certamente se agravaram com o avanço tecnológico, de modo que a preocupação com o destino do nosso planeta é também uma preocupação com as relações que as pessoas estabelecem com o ambiente. A psicologia ambiental busca construir modelos explicativos para tal interação, considerando a influência recíproca entre as pessoas e o ambiente. Entre outras contribuições à psicologia ambiental, a teoria das representações sociais tem se mostrado de grande valor para a compreensão desta complexa relação. No campo ambiental a teoria das representações sociais tem assumido um valor incontestável na busca da compreensão das dinâmicas sociais, pois permite conhecer os processos cognitivos e simbólicos que norteiam as práticas direcionadas ao mundo que nos cerca. Esse estudo teórico busca colocar em pauta as contribuições que a teoria das representações sociais pode trazer a compreensão da relação entre pessoa e ambiente.
\end{abstract}

Palavras-chave: psicologia ambiental; psicologia social; teoria das representações sociais; meio ambiente.

\begin{abstract}
Possibility of use social representation theory to environmental-person studies. The environmental problems generated by the human behavior are old, but they are aggravated with the technological advance, in way the concern with the destination of our planet is also a concern with the relations the people establish with the environment. Environmental psychology inquires to construct clarifying models for such interaction, considering the reciprocal influence between the person and the environment. Among others contributions to environmental psychology, the social representations' theory has shown of great value for the understanding this complex relation. In the environmental field the social representations' theory has an undisputed value in the search of the social dynamic's understanding. It allows knowing cognitive and symbolic processes that guide the practical ones directed to the world around us. This theoretical study inquires to place in guideline the contributions that the social representations' theory can bring the understanding the relation between person and environment.
\end{abstract}

Keywords: environmental psychology; social psychology; social representations' theory; environment.

\section{A psicologia e os problemas humano-ambientais}

Os problemas ambientais gerados pelo comportamento humano são bastante antigos, mas certamente se agravaram com a nova maneira de produzir a partir do avanço tecnológico da era moderna que, pela utilização de máquinas e outros procedimentos, tem sido hábil em destruir a natureza. A noção de que os recursos naturais são infindáveis, bem como sua visão utilitária, avançou no mesmo ritmo da perda de respeito pela sua fragilidade e finitude. Estes fatores reunidos configuram o campo em que ocorre o comportamento de deterioração do meio ambiente. Infelizmente, muitas tentativas de explicá-lo caracterizam-se pela parcialidade, pois a predominância da preocupação com o pólo humano na relação deixa de lado a noção de interação entre natureza e humanidade. Deve-se escapar da armadilha da parcialidade conferindo à história, à cultura, à ideologia e às representações sociais papéis fundamentais para compreender como tais comportamentos se instalam e como podem ser transformados. As palavras de Daniel Cohn-Bendit a respeito de ecologia, proferidas em uma intervenção durante a conferência Da ecologia à autonomia, ocorrida em 1980 na Bélgica, são elucidadoras:

Para mim, a ecologia não é apenas um problema de relações sociais de um homem com outro homem; é o problema da relação do ser humano com a natureza e com os outros homens. A ecologia não é tão pouco a defesa do meio ambiente; isso é apenas uma parte do programa... eu defendo um ecossistema, no interior do qual existem relações sociais (Castoriadis \& Cohn-Bendit, 1981, p. 82).

A centralidade da questão ambiental no século $\mathrm{XX}$ é 
apresentada por muitos autores que prescrevem à humanidade o enfrentamento de suas responsabilidades frente ao futuro da natureza. Ou seja, como diz Moscovici em seu livro Essai sur l'histoire de la nature (1977): “de fato, é preciso substituir um quadro que nos parecia dado por um quadro que façamos nós mesmos." (p. 12). Segundo o autor, devemos aceitar "lucidamente o encargo da natureza, seu passado e seu vir-a-ser, da mesma forma que no século passado os homens aceitaram o mesmo dever e a mesma responsabilidade sobre o plano da sociedade" (p. 24). O contexto espacial e temporal da relação sociedade/meio ambiente, assim como certas dimensões relativas ao indivíduo, como a etapa do ciclo de vida, o projeto, o modo de vida, o apego afetivo, a expressão identitária e simbólica, as aspirações e os valores constituem-se num agrupamento de fatores que têm um peso importante na avaliação do meio.

Pode-se, então, afirmar que a preocupação com o destino do nosso planeta é também uma preocupação com as relações que as pessoas estabelecem com o seu entorno. Por este motivo, nas últimas décadas percebe-se um crescente interesse pelos aspectos psicológicos envolvidos nesta relação. A crise ambiental é, na verdade, uma crise na relação pessoa-ambiente, e os grandes problemas ambientais são visualizados como problemas humano-ambientais (Pinheiro, 2002).

O estilo de vida individualista adotado pelos seres humanos na sociedade atual, pautado pela satisfação das necessidades pessoais e pelo consumismo, pode ser considerado o principal responsável pelos problemas ambientais como a degradação das matas, o aquecimento global e a poluição das águas, entre outros. O equacionamento de tais problemas implica mudança de atitude e comportamento, para tanto sendo necessário buscar compreender o que vem ocorrendo ao planeta a partir de uma perspectiva em que a natureza seja considerada em inter-relação com o comportamento humano (García-Mira, Sabuccedo, \& Real, 2002; Pinheiro, 2003; Pol, 1993). Desta forma as ciências sociais e do comportamento têm se voltado para as questões ambientais em busca da compreensão das relações entre a pessoa e o entorno, considerando a influência que o meio exerce sobre a pessoa, bem como a influência que a pessoa exerce sobre o meio. Como consequência, tem-se na psicologia ambiental a busca de modelos explicativos para tal interação, modelos estes que visam compreender a dimensão humana implicada no ambiente (García-Mira, Sabucedo, \& Real, 2002; Kuhnen, 1995; 2002).

\section{A Psicologia Ambiental}

A psicologia ambiental caracterizou-se enquanto área ou campo de estudo no contexto dos problemas humano-ambientais com o objetivo de fornecer modelos explicativos para a interação entre a pessoa e o ambiente. Ela surgiu como uma área aplicada, com o objetivo de resolver problemas relacionados a essa interação, e tem duas grandes origens, uma interna e outra externa à própria psicologia. $\mathrm{Na}$ vertente externa as principais influências vieram da arquitetura e planejamento urbano, da geografia e ciências bio-ecológicas; na vertente interna, duas importantes áreas, a psicologia da percepção, que define o ambiente em termos físicos e perceptuais, e a psicologia social, voltada para um aspecto mais molar, oferecem suporte para o desenvolvimento da área (Pinheiro, 2003).
Desde o início, para estudar a relação pessoa-ambiente, a psicologia ambiental beneficiou-se tanto de teorias quanto de métodos desenvolvidos pela ciência psicológica. Entretanto, na medida em que estudos empíricos e teóricos foram desenvolvidos, alguns conceitos e métodos próprios também foram sendo elaborados. Entre eles tem-se os conceitos de competência pró-ambiental, identidade de lugar, apego ao lugar, cognição ambiental e espaço pessoal, entre outros (Polli, 2008). Alguns métodos de pesquisa também foram sendo empiricamente testados. Recentemente, uma publicação inédita no Brasil divulgou em nosso meio alguns destes métodos: o livro Métodos de pesquisa nos estudos pessoa-ambiente (Pinheiro \& Günther, 2008) é um bom exemplo de que a pesquisa na área no Brasil tem produzido subsídio para o estudo da relação pessoa-ambiente.

Rabinovich (2005) explicou que a psicologia ambiental se preocupa em estudar o ambiente concreto e sua influência nos modos de vida das pessoas. Estudos mostram que a elaboração das imagens espaciais dos indivíduos são influenciadas pelas representações sociais (Aragonés, 1998; Bonfim \& PolUrrutia, 2005). Se considerarmos a sócio-espacialidade das representações, veremos que a orientação afetiva dos habitantes de uma cidade ou bairro aparece nas práticas urbanas e está em correspondência com os lugares escolhidos para se estar, por exemplo. Se o espaço adquire significados, a observação das mudanças realizadas no ambiente físico (natural ou construído) e as descrições das atividades desenvolvidas em certos contextos ambientais podem indicar qual é o papel que o ambiente físico exerce sobre o comportamento social. O papel exercido pelo indivíduo deve também ser levado em conta, bem como as regras sociais do local, que são apreendidas e repassadas. Os espaços e as coisas, que têm um papel ativo no mundo referencial de uma coletividade, repercutirão no surgimento de significados através do tempo. Os objetivos dos indivíduos em uma determinada situação são organizados e estruturados pelos processos sociais ou organizacionais que, associados a determinadas ações, são desenvolvidos em situação, ou seja, em um lugar específico. Recebem a influência de uma série de intervenientes, entre eles as experiências anteriores dos sujeitos. Portanto, há uma interdependência entre o ambiente e o comportamento, pois ocorre uma dinâmica de troca entre a pessoa e o ambiente que, entretanto, não deve ser dissociado do contexto social. Por último cabe destacar que "o indivíduo é um sujeito ativo que interpreta o meio com o qual interage, e constró $i$ seu ambiente" (Ramandier, 1997, p. 37).

Assim, quando se fala sobre a influência do ambiente sobre o comportamento humano (ambiente $\rightarrow$ comportamento), considera-se o ambiente não apenas como contexto no qual ocorre a atuação humana, mas como o conjunto de estímulos que interferem nesta atuação tendo um efeito sobre a pessoa ou grupo, podendo ser esse efeito consciente ou atuar sobre a pessoa sem que ela se dê conta de que está sofrendo qualquer influência. Sob esse aspecto, o ambiente pode ser considerado de três formas distintas: primeiramente enquanto ambiente natural, considerando o efeito do ecossistema sobre o comportamento molar das pessoas; a segunda forma seria como ambiente construído, por meio de suas características físicas, que 
podem ser mais móveis ou mais fixas e permanentes, como decoração ou construção, respectivamente; por último, como ambiente social ou cultural, em que aspectos como espaço pessoal, intimidade, privacidade e territorialidade, entre outros, possuem especial significação (Burillo, 1991). Os estudos sobre a representação social do ambiente têm a influência do ambiente no comportamento como foco, mas permitem que o outro elo da relação também possa ser identificado, já que as representações sociais são prescritoras de comportamento. Assim, as representações sociais possibilitam trabalhar também com a vertente complementar, que busca compreender a forma como o comportamento humano interfere no ambiente (comportamento $\rightarrow$ ambiente). Neste campo se destacam os estudos sobre conduta protetora do ambiente, habilidades próecológicas e comportamento de preservação. Não há duvida de que a busca pela preservação do ambiente é também a busca da mudança de comportamento, a busca de um comportamento ambientalmente sustentável. A mudança de comportamento possui aspectos muito importantes a serem considerados, como as atitudes, crenças, representações e valores, que entre outros podem motivar as pessoas a desenvolver condutas efetivas de proteção ambiental. Ao se estudar o efeito do comportamento sobre o ambiente é importante estudar as influências ambientais que são responsáveis pelo comportamento de preservação do entorno, como a presença de lixeiras nas ruas, que servem de estímulo para que lixo não seja descartado em local inapropriado (Corral-Verdugo, 2003, 2005; García-Mira, Sabucedo, \& Real, 2002).

Portanto, a psicologia ambiental trata da pessoa e do ambiente, mas não separadamente, trata da inter-relação que existe entre eles, de forma que se pode dizer que a relação pessoa-ambiente é o objeto de estudo da psicologia ambiental, que busca compreender a influência do ambiente sobre a pessoa e a influência da pessoa sobre o ambiente, em uma relação bidirecional em que não se pode determinar o ponto de partida, compondo uma interação constante e que não pode ser separada, a não ser didaticamente (Moser, 2005; Pinheiro, 2003, 2005; Rivlin, 2003).

Mas, apesar do avanço interno à própria psicologia ambiental, esta sub-área tem mostrado que, acima de tudo, o diálogo teórico-metodológico é necessário quando estamos tratando das questões ambientais. E, sendo assim, mantém-se aberta à contribuição de outras áreas, sejam externas ou internas à psicologia. $\mathrm{O}$ diálogo com a psicologia social continua frutífero e exemplos disso são os estudos que se beneficiam da teoria das representações sociais (Castro, 2003; Jodelet, 1996, 2002; Kuhnen, 1995, 2002; Moser, Ratiu, \& Vanssay, 2005; Peluso, 2003; Reigota, 2004; Rouquette, Sautkina, Castro, Felonneau, \& Guillou-Michel, 2005).

\section{A importância das representações sociais na compre- ensão da relação pessoa-ambiente}

Se concordarmos que o pensamento científico desenvolvese em função da demanda social, ou seja, que há uma tentativa de responder às interrogações que a sociedade se coloca ou a equacionar problemas que surgem, o que podemos dizer da verdadeira explosão de estudos sobre representações nos últimos tempos? Tanto no campo das ciências quanto em outras dimensões da vida, como na arte, na religião, na política e até nas tecnologias - a exemplo da mídia e das inovações no campo das tecnologias dirigidas a mitigar os problemas causados pela humanidade ou aqueles que são de ordem natural -, a questão de como o ser humano representa o mundo vem fazendo parte das grandes discussões nas últimas décadas.

Mas, o conceito de representação não é simples e nem consensual. Talvez a questão mais aglutinadora seja que o acesso à representação vincula-se ao conhecimento que transcende a aparência das coisas, de modo que o que é representado não coincide com a realidade concreta e material. Ao entender a representação de tal forma, quase todos os aportes teóricos se voltam para o cotidiano ou o vivido, centrando aí sua fonte de conhecimento. Sabemos que o conhecimento das representações humanas evidencia a maneira como os sujeitos sociais apreendem os acontecimentos da vida diária, as características do meio, as informações que circulam, as relações sociais.

As representações sociais são tanto um conjunto de fenômenos quanto um conceito que se refere a uma teoria que busca explicá-los, configurando-se como um campo de estudos psicossociológicos. A teoria das representações sociais teve origem na Europa, dentro do campo da Psicologia Social, com a publicação de La Psychanalise:son image et son publique por Serge Moscovici em, 1961, na França. No Brasil foi traduzido em 1978 com o título A Representação Social da Psicanálise. Neste estudo, Moscovici buscou compreender a representação social da psicanálise da população parisiense, e conseguiu redefinir os problemas e os conceitos da psicologia social a partir do estudo do fenômeno das representações sociais (Moscovici, 1978).

O conceito de representações sociais não costuma ser definido de maneira precisa, pois Moscovici (1978) julgou que uma caracterização, definida de tal forma, resultaria em uma redução de sua abrangência conceitual. Já Wagner (1998) aponta alguns caminhos para definir o que seja uma representação social:

Um conteúdo mental estruturado - isto é, cognitivo, avaliativo, afetivo e simbólico - sobre um fenômeno social relevante, que toma a forma de imagens ou metáforas, e que é conscientemente compartilhado com outros membros do grupo social. (...) a representação social é vista como um processo público de criação, elaboração, difusão e mudança do conhecimento compartilhado no discurso cotidiano dos grupos sociais. (...) ou em outras palavras: representação social é definida como a elaboração de um objeto social pela comunidade. (pp. 3-4)

Sá (1996) considera que apesar de sua complexidade e dificuldade de definição alguns autores têm buscado caracterizar as representações sociais (como o já citado Wagner), de forma que Jodelet (2001) caracteriza a representação social como "uma forma de conhecimento socialmente elaborada e partilhada, com um objetivo prático, e que contribui para a construção de uma realidade comum a um conjunto social" (p. 22). Para evitar a redução do conceito a uma frase, a autora acrescenta informações importantes: representação social é a significação que um grupo de pessoas atribui a um objeto social. É representação porque é dotada de significado e é social porque tem origem nas relações sociais e é partilhada pelo grupo por meio da comunicação. 
Apesar de se manifestarem como elementos cognitivos, as representações sociais não se limitam a esta característica, pois são elaboradas e compartilhadas socialmente, contribuindo, desta forma, para a construção de uma realidade comum, que possibilita a comunicação social (Jodelet, 1993). As representações sociais são ativadas na vida social, e seus elementos constituem um saber que diz algo sobre a realidade, resultam em um saber do senso comum, que apesar de diferenciado do conhecimento científico pode ser influenciado por este (Jodelet, 2001).

Apesar de ser comum a um determinado grupo social, não se pode dizer que as representações sociais sejam consensuais, e a pluralidade que lhe é característica permite compreender a variedade de expressões individuais de uma representação. Essa variedade pode dar a impressão de representações distintas que, no entanto, tem sua origem em princípios organizadores comuns. O que permite uma distinção das representações sociais é o fato de serem vinculadas a inserções sociais específicas e determinadas práticas de comunicação socialmente definidas. As representações sociais possibilitam uma articulação entre os sistemas de comunicação e os sistemas de organização cognitiva (Sá, 1996). Portanto, se pode dizer que um determinado grupo social tende a ter uma representação social comum em relação a um determinado objeto, muito embora essa tendência não permeie todo o grupo, ocorrendo variações (expressões individuais) que têm origem comum, pois a comunicação dentro de um grupo específico permite a elaboração das representações sociais.

Nesse contexto cabe situar a diferenciação que o termo sociais, introduzido por Moscovici, expressa em relação ao termo coletivas utilizado por Durkheim. Moscovici (1989, 2003) afirma que o conceito de representação social teve sua origem no conceito de representações coletivas de Durkheim. O autor estudou as representações coletivas, as quais considerou objeto da sociologia, e procurou distinguir das representações individuais, para ele, objeto da psicologia (Duveen, 2003; Kuhnen, 1995, 2002). As representações coletivas são "produções sociais que se impõe aos indivíduos como forças exteriores e que teriam o papel de imprimir coesão social"' (Kuhnen, 2002, p. 55).

Moscovici usou o termo sociais e não o termo coletivas, para enfatizar o caráter dinâmico das representações. As representações coletivas tinham, para Durkhein, a função de ajudar a integrar e conservar a sociedade, Moscovici, no entanto, buscou compreender como as representações sofrem transformações na sociedade. As representações coletivas de Durkhein são formas estáveis de compreensão coletiva, que servem para integrar a sociedade como um todo (Duveen, 2003). A teoria das representações sociais de Moscovici está pautada na ideia de que as representações criam realidade e senso comum e não apenas designam uma classe de conhecimentos e crenças coletivas, conforme Durkhein considerou ao falar em representações coletivas (Kuhnen, 2002).

Moscovici (1978) enfatiza que a diferenciação entre as representações sociais e outros sistemas de pensamento coletivo (por exemplo, a ideologia) está na medida em que a representação social é elaborada no decorrer do processo de comunicação social. A representação social é um guia para a ação, e uma das suas funções essenciais é contribuir para a formação de processos que orientam a comunicação e o comportamento social (Guimelli, 1993).

Abric $(1994,1998)$ aponta algumas funções fundamentais das representações sociais indicadas na Tabela 1:

A estrutura das representações sociais possui uma dupla natureza, de modo que a representação ocorre por meio de um processo de trocas entre um conceito e uma percepção, possuindo um caráter conceitual e um caráter figurativo - um conceito e uma imagem. De um lado, a representação é moldada pelo

Tabela 1

Funções da representação social

\begin{tabular}{ll}
\hline Função & \multicolumn{1}{c}{ Finalidade } \\
\hline Saber & Compreender e explicar a realidade; \\
& Saber prático do senso comum; \\
& Assimilar conhecimentos em um sistema cognitivo existente; \\
& Comunicação social; \\
& Trocas sociais; \\
& Transmitir e difundir o saber do senso comum. \\
& Definir identidade grupal; \\
& Preservar as particularidades de dado grupo; \\
& Situar os indivíduos dentro de um grupo social compatível com o sistema \\
de normas e valores determinados social e historicamente. & \\
& Guiar comportamentos e práticas; \\
& Orientar a conduta; \\
Orientação & Definir o tipo de estratégia cognitiva a ser adotada; \\
& Criar modelos de antecipação e justificativas da ação; \\
& Definir o que é lícito, tolerável ou inaceitável em um determinado \\
& contexto social. \\
& Justificar posteriormente as tomadas de decisão e os comportamentos; \\
& Criar representações que justificam suas ações; \\
& Preservar e justificar a diferenciação social, podendo contribuir para a \\
discriminação ou manutenção da distância entre grupos; \\
É determinada pela prática das representações.
\end{tabular}


pensamento conceitual, de modo que o objeto representado pode estar ausente e mesmo assim pode ser concebido, dotado de sentido, simbolizado, nomeado; por outro lado, a atividade perceptiva cria uma imagem do objeto, uma figura, um ícone, de modo que ele se torna algo tangível, e pode ser visualizado. Esse processo é responsável pela reinvenção de dado objeto da realidade por meio de uma representação. Portanto, a representação não é mera cópia do objeto representado, mas uma modificação, uma reinvenção: o objeto representado é diferente do objeto real, e tais modificações têm origem no psiquismo individual e social (Moscovici, 1978).

A estrutura da representação também possui duas faces, uma figurativa e uma simbólica, de modo que todo o sentido pressupõe uma figura e toda figura pressupõe um sentido. Essa estruturação permite compreender os processos de objetivação e ancoragem, que são dois processos distintos que ocorrem na formação da representação. Quando um sentido é dado para uma figura, de forma a dar materialidade a um objeto abstrato, ocorre o processo de objetivação; a reprodução de uma figura por um sentido, na qual se contextualiza um objeto, ocorre no processo de ancoragem (Sá, 1996). Por sua vez, Jodelet (2001), explica o papel da ancoragem na formação das representações sociais:

A ancoragem intervém ao longo do processo de formação da representação, assegurando sua incorporação ao social. Por um lado, a ancoragem enraíza a representação e seu objeto numa rede de significações que permite situá-los em relação aos valores sociais e dar-lhes coerência. (p. 38)

Trata-se da representação de um novo objeto por meio de sua integração com um sistema de pensamento social préexistente, ou seja, incorporação de elementos novos a um sistema existente de categorias, de modo a tornar o que é novo familiar, nomeando e classificando (Sá, 1996). A ancoragem permite apoiar a novidade em esquemas antigos, ao que já é conhecido. Ela torna possível dar funcionalidade a uma representação, de modo a interpretar e gerir o ambiente (Jodelet, 2001).

A objetivação é processo pelo qual um objeto passa a ser imaginado, recriado, ganha forma, deixa de ser um conceito abstrato para tornar-se concreto, é a transformação de um conceito em uma imagem. É a criação imagética de algo que se equivale às palavras, seu equivalente não verbal. Os dois processos - objetivação e ancoragem - são formadores da representação e permitem a familiarização do não familiar (Sá, 1996).

O modelo teórico das representações sociais impulsiona a invenção e a diversidade e coloca em pauta a complexidade que permeia a formação de pensamentos, ideias, conceitos, imagens e conhecimento a partir do social e da comunicação. Permite compreender o processo pelo qual o desconhecido passa a ser comum, conhecido. Põe em voga a mudança, a modificação, as alterações e a mutabilidade que a verdade possui; as representações sociais não são estáticas, estão em movimento, e esse movimento ocorre dentro do mundo das relações sociais (Polli, 2008).

Guimelli (1993) informa que um grande número de estudos experimentais permitiu demonstrar que o comportamento individual ou grupal não é determinado pelas características objetivas da situação em que as pessoas se encontram, mas pela representação que possuem da situação ou de dado objeto. Nesse sentido a teoria das representações sociais permite uma melhor compreensão sobre os valores, atitudes, opiniões e comportamentos.

\section{Representações Sociais e Psicologia Ambiental}

No campo ambiental a teoria das representações sociais tem um valor incontestável na busca da compreensão das dinâmicas sociais. Ela permite conhecer os processos cognitivos e simbólicos que norteiam as práticas direcionadas ao mundo que nos cerca. Quando nos voltamos à compreensão da atuação humana no ambiente, atuação esta de grande complexidade, a teoria das representações sociais possibilita compreender os comportamentos direcionados ao meio ambiente. Portanto, os problemas sociais podem ser tratados de maneira direcionada. A representação permite que as pessoas possam ajustar-se ao ambiente social e material pautando suas ações em uma atividade de construção mental e social do mundo real (Jodelet, 1996).

As relações das pessoas com o meio ocorrem a partir da representação que a pessoa elabora do ambiente, formadas por seus valores, expectativas e preferências. A atuação da pessoa sobre o ambiente é influenciada tanto por relações individuais que estabelece com o meio, quanto pelos valores sociais que possui em relação ao ambiente. As representações assumem o papel de organizar e estruturar o real em um sistema cognitivo coerente que permite que a pessoa possa entender o mundo e atuar sobre ele. As características pessoais, as experiências passadas e presentes na relação com o ambiente, incluindo a cultura e a antecipação do que possa acontecer no futuro determinam esse sistema (Moser, Ratiu, \& Vanssay, 2005).

Ao buscar aproximar a cognição e o significado espacial, Valera (2002) se refere ao significado que atribuímos ao ambiente, enfatizando que esse significado é vivido e reinventado individualmente (em cada pessoa). No entanto, continua o autor, o significado tem uma origem social que se forma na interação entre as pessoas e o ambiente, que se definem um ao outro na atuação e com base na linguagem. Assim sendo, a linguagem possibilita a criação e o compartilhamento de imagens, símbolos e significados ambientais que se relacionam com a pessoa ou com sua identidade espacial. É por meio da linguagem que a representação do meio ambiente supera seu caráter físico e atinge sua dimensão social.

Segundo Jodelet (2002), considerando que é da relação pessoa-ambiente que trata a psicologia ambiental, a teoria das representações sociais se aproxima de tal objeto, pois as representações do espaço são também representações sociais. Para esta pesquisadora a teoria das representações sociais se apresenta como um meio para superar a dificuldade de colocar em pauta a dimensão social que a psicologia ambiental busca identificar como um fator determinante na relação pessoaambiente. A teoria das representações sociais permite que fatores como conhecimento, crenças e valores possam ser incorporados aos estudos em psicologia ambiental (Rouquette et al., 2005).

A psicologia ambiental e a teoria das representações sociais possuem muitos aspectos em comum, ou áreas de convergência, que se pautam em algumas hipóteses enumeradas 
por Jodelet (1996): A primeira delas se refere à ideia de que todo conhecimento do ambiente é mediatizado pelo plano da percepção, da interpretação e da ação, pelas representações sociais. "Estas representações são modalidades de conhecimento que (...) dizem algo sobre o estado deste mundo e dos objetos que o constituem" (p. 29), de modo que funcionam como filtros de interpretação e guias de ação. Uma segunda hipótese apontada pela autora se refere ao caráter social das representações que tem origem na comunicação social. As representações são compartilhadas pelos sujeitos sociais, contribuindo para a construção de uma realidade consensual: “as representações são conhecimentos práticos e orientam condutas e comunicações sociais" (Jodelet, 1996, p. 30). A terceira hipótese trata das consequências para o plano cognitivo do caráter social que a representação possui. Seu caráter social afeta o conhecimento que as pessoas possuem sobre os conteúdos, sobre os processos e sobre a forma que possui dado objeto. As representações possuem também um caráter voltado para os valores, necessidades e interesses pessoais e grupais.

Nessa direção Valera (2002) também traz informações importantes sobre as representações do ambiente:

É possível pressupor que as pessoas desenvolvem representações sobre o nosso entorno físico a partir de um conjunto de informações socialmente compartilhadas que, mais que mero reconhecimento de elementos espaciais e sua disposição e estrutura, e ancoradas no senso comum e em nosso contexto cultural, atuam como verdadeiras teorias sobre como é nosso ambiente, o que podemos esperar e como devemos nos relacionar com ele. Isto permite, através de uma série de processos cognitivos, simplificar a grande quantidade de estímulos ambientais que nos chegam, capturando aqueles que socialmente parecem essenciais para interagir com o ambiente. (p. 135)

No campo ambiental, o estudo das representações sociais permite compreender como objetos do campo material, social ou ideal são compreendidos e formam os conhecimentos que servirão de base para a interpretação da realidade e sobre o qual se pautarão as ações. As representações sociais relacionadas aos objetos de estudo próprios da psicologia ambiental permitirão conhecer as percepções e concepções dos sujeitos sociais sobre o ambiente físico e os problemas ambientais, tendo em conta as dimensões simbólicas e culturais da vida coletiva e individual, que servem de base para as experiências cotidianas em relação ao ambiente (Jodelet, 1996). Nesta perspectiva se inserem a maior parte dos trabalhos sobre o modo como o sujeito representa o ambiente, relacionando-o com sua história, suas experiências, seus afetos ou mesmo de sua competência ambiental.

No Brasil, Reigota (2004) lançou uma coletânea de artigos intitulada Meio Ambiente e Representação Social (primeira versão de 1994), na qual discute importantes aspectos relacionados à educação ambiental, aos principais problemas ambientais da América Latina e as implicações da representação social do meio ambiente na prática pedagógica. $\mathrm{O}$ autor verificou que as representações sociais do meio ambiente e da educação ambiental eram ainda embrionárias, já que os dados foram coletados entre 1991 e 1993, quando as discussões ambientais recebiam menor ênfase ou, mesmo, divulgação menos efetiva. As representações sociais que os professores elaboravam exerciam influência sobre a prática pedagógica que adotavam em sala de aula, em geral, voltadas para uma educação ambiental preservacionista, já que tinham uma representação social do meio ambiente bastante naturalista, em que apenas os aspectos naturais ganhavam destaque.

Em estudo mais recente, Martinho e Talamoni (2007) investigaram as representações sociais do meio ambiente em 42 alunos do ensino fundamental. As representações encontradas foram naturalistas e antropocêntricas, ou seja, os estudantes ressaltaram noções relativas aos aspectos naturais do meio ambiente, bem como a utilidade dos recursos naturais para a sobrevivência dos seres humanos.

Buscando avaliar os resultados de um programa de coleta seletiva de lixo implantado na cidade de Florianópolis, Kuhnen (1995) procurou conhecer as representações sociais do lixo da população da cidade. Um programa de educação ambiental vinha sendo desenvolvido pela agência responsável pela coleta do lixo, e a autora teve uma grata surpresa ao verificar que, ainda em um momento em que valores ligados a preservação ambiental ganhavam pouco destaque (início dos anos 90), a população vinha se comprometendo com a separação do lixo, motivados pela valorização do meio ambiente, por sentirem-se parte dele e pela solidariedade social. As representações sociais da população que se preocupava com a cidade, com o lixo nas ruas, com a saúde, com a preservação ambiental, traduzia-se em comportamentos e estas pessoas passavam a separar o lixo reciclável dos rejeitos não aproveitáveis.

Em Portugal, Castro (2003) procurou identificar as representações sociais do ambiente e da natureza. A autora verificou que a representação social era composta por ideias ecológicas de que a terra tem limitações de espaço e de recursos, e que as pessoas estão sujeitas a tais limites, mas que têm utilizado os recursos naturais sem critério e, portanto, comprometem o equilíbrio natural. Por outro lado, encontrou-se uma ideia diversificada, antropocêntrica, em que as pessoas acreditam que os seres humanos são capazes de domar a natureza e a ciência é capaz de fornecer explicações para os fatos. A autora verificou que a ideia ecológica predominava em relação à antropocêntrica, indicando que a visão da natureza e do ambiente como elementos que precisam ser cuidados pelos seres humanos vem se tornando uma normativa e ganha espaço no discurso popular.

\section{Considerações finais}

Pode-se concluir que a importância de conhecer as representações sociais de aspectos ambientais reside no fato de que a representação social do ambiente traduz o modo como se dá a relação do sujeito com seu entorno. Elas constituem o eixo entre os contextos ambiental e social, e evidenciam as relações da pessoa com o ambiente, que ocorrem de acordo com sua função social. As representações sociais determinam as condições nas quais as pessoas percebem e se relacionam com as situações concretas (Moser, Ratiu, \& Vanssay, 2005).

Ao se estudar representações sociais deve-se ter em mente que a realidade social institui o sujeito individual e que 
elas emergem expressando a subjetividade do campo social e sua capacidade de construir saberes. Mas, como construções particularizadas deste campo, não podem ser reduzidas a um conjunto em que as partes são as representações individuais, visto que se formam e se transformam, valendo-se da comunicação e das práticas sociais, que são, enfim, as mediações sociais. Estas mediações acabam por gerar saberes como representações sociais que, coletivamente, transcendem a produção individual e que são elas mesmas, também mediações sociais. Tal processo nos faz ver que a experiência humana não é direta, mas mediada, tendo também o ambiente um papel muito importante na tentativa humana de dar sentido e entender a vida. Tendo em vista que os símbolos aproximam o sujeito do objeto ausente (como, por exemplo, a água), o processo de simbolização constitui uma importante via para se conhecer aspectos da relação pessoaambiente, como têm mostrado os estudos do fenômeno das representações sociais.

\section{Referências}

Abric, J-C. (1994). Les représentations sociales: aspects théoriques. In J-C Abric (Org.), Pratiques Sociales \& Représentations (pp. 11-35). Paris: Press Universitaires de France.

Abric, J-C. (1998). A abordagem estrutural das representações sociais. In A. S. P. Moreira, \& D. C. Oliveira (Orgs.), Estudos interdisciplinares de representação social (pp. 27-38). Goiânia: AB Editora.

Aragonés, J. I. (1998). Cognición Ambiental. In J. I. Aragonés, \& M. Amérigo (Orgs.), Psicología Ambiental (pp. 43-58). Madrid: Pirámide.

Bomfim, A. A. C., \& Pol-Urrutia, E. (2005). Affective dimension in cognitive maps of Barcelona and São Paulo. International Journal of Environmental Psychology, 40(1), 37-50.

Burillo, F. J. (1991). Historia, concepto y teorias en psicología ambiental. In F. J. Burillo, \& J. I. Aragonés (Orgs.), Introducción a la Psicología Ambiental (pp. 21-32). Madrid: Alianza Psicología.

Castoriadis, C., \& Cohn-Bendit, D. (1981). O público de Louvain-la-Neuve: da ecologia à autonomia. Coimbra: Centelha.

Castro, P. (2003). Pensar a natureza e o ambiente - alguns contributos a partir da teoria das representações sociais. Estudos de Psicologia, 8(2), 263-271.

Corral-Verdugo, V. (2003). Determinantes psicológicos e situacionais do comportamento de conservação de água: um modelo estrutural. Estudos de Psicologia, 8(2), 245-252.

Corral-Verdugo, V. (2005). Psicologia ambiental: objeto, "realidades" sócio-físicas e visões culturais de interações ambiente-comportamento. Psicologia USP, 16(1/2), 71-87.

Duveen, G. (2003). O poder das idéias. In S. Moscovici (Org.), Representações sociais: investigação em psicologia social (pp. 7-28). Petrópolis: Vozes.

García-Mira, R., Sabucedo, J. M., \& Real, J. E. (2002). Medio ambiente y comportamiento humano. In: R. García-Mira, J. M. S. Cameselle, \& J. R. Martinez (Orgs.), Psicologia y medio ambiente: aspectos psicosociales, educativos y metodológicos (pp. 29-53). Espanha: Universidade de Santiago de Compostela.

Guimelli, C. (1993). Concernig the structure of social representations. Papers on Social Representations, 2(2), 85-92.

Jodelet, D. (1993). O conceito de representação social na abordagem psicossocial. Cadernos de Saúde Pública, 9(3), 300-308.

Jodelet D. (1996). Las Representaciones sociales del medio ambiente. Coleccion Monografias Psico/Socio/Ambientals, 9, 29-44.

Jodelet, D. (2001). Representações sociais: um domínio em expansão. In D. Jodelet
(Org.), As representações sociais (pp. 17-44). Rio de Janeiro: EDUERJ. Jodelet, D. (2002). A cidade e a memória. In V. Del-Rio, C. R. Duarte, \& P. A. Rheingantz (Orgs.), Projeto de lugar: colaboração entre psicologia, arquitetura e urbanismo (pp. 31-43). Rio de Janeiro: Contra Capa.

Kuhnen, A. (1995). Reciclando o cotidiano: representações sociais do lixo. Florianópolis: Letras Contemporâneas.

Kuhnen, A. (2002). Lagoa da conceição: meio ambiente e modos de vida em transformação. Florianópolis: Cidade Futura.

Martinho, L. R., \& Talamoni, J. L. B. (2007). Representações sobre meio ambiente de alunos da quarta série do Ensino Fundamental. Ciência \& Educação, 13(1), 1-13.

Moscovici, S. (1977). Essai sur l'histoire de la nature. Paris: Champs/Flammarion.

Moscovici, S. (1978). A representação social da psicanálise. Rio de Janeiro: Zahar.

Moscovici, S. (1989). Des représentations collectives aux représentations sociales. In D. Jodelet (Org.). Les représentations sociales (pp. 62-86). Paris: Presses Universitaires de France.

Moscovici, S. (2003). Representações Sociais: investigação em psicologia social. Petrópolis: Vozes.

Moser, G. (2005). A psicologia ambiental: competência e contornos de uma disciplina. Comentários a partir das contribuições. Psicologia USP, 16(1/2), 279-294.

Moser, G., Ratiu, E., \& Vanssay, B. (2005). Pensar en el água: representaciones sociales, ideologías y prácticas: un modelo de las relaciones con el agua en diferentes contextos societales. Trayectorias, 7(18), 79-91.

Peluso, M. L. (2003). O potencial das representações sociais para a compreensão interdisciplinar da realidade: geografia e psicologia ambiental. Estudos de Psicologia, 8(2), 321-327.

Pinheiro, J. Q. (2002). Comprometimento ambiental: perspectiva temporal e sustentabilidade. In J. G. Martínez, \& S. M. Doménech (Orgs.), Temas selectos de psicología ambiental (pp. 463-481). México: UNAM-GrecoFundación Unilibre.

Pinheiro, J. Q. (2003). Psicologia ambiental brasileira no início do século XXI: sustentável? In O. H. Yamamoto, \& V. V. Gouveia (Orgs.), Construindo a psicologia brasileira: desafios da ciência e prática psicológica (pp. 279-313). São Paulo: Casa do Psicólogo.

Pinheiro, J. Q. (2005). O lugar e o papel da psicologia ambiental no estudo das questões humano-ambientais, segundo grupos de pesquisa brasileiros. Psicologia USP, 16(1/2), 103-113.

Pinheiro, J. Q., \& Günther, H. (2008). Métodos de pesquisa nos estudos pessoaambiente. São Paulo: Casa do Psicólogo.

Pol, E. (1993). Environmental psychology in Europe: from architectural psychology to green psychology. Aldershot: Avebury.

Polli, G. M. (2008). Representações sociais da água e tecnologias sociais (Dissertação de Mestrado não-publicada). Universidade Federal de Santa Catarina, Florianópolis.

Rabinovich, E. P. (2005). Por uma psicologia ambiental das diferenças. Psicologia USP, 16(1/2), 119-127.

Ramandier, T. (1997) Construction cognitive des images de la ville: evolution de la représentation cognitive de Paris auprès d'etudiants étrangers (Tese de doutorado não publicada). Universidade René Descartes, Paris V, Paris.

Reigota, M. (2004). Meio ambiente e representação social. São Paulo: Cortez.

Rivlin, L. G. (2003). Olhando o passado e o futuro: revendo pressupostos sobre as inter-relações pessoa-ambiente. Estudos de Psicologia, 8(2), 215-220.

Rouquette, M. L., Sautkina, E., Castro, P., Felonneau, M. L., \& Guillou-Michel, E. (2005). Social representations theory and environmental studies. In B. Martens \& A. Keul (Orgs.), Designing social innovation - planning, building, evaluating (pp. 107-115). Göttingen: Hogrefe \& Huber.

Sá, C. P. (1996). Núcleo central das representações sociais. Petrópolis: Vozes. 
Valera, S. (2002). Medio ambiente y representación social: una visita a la ciudad como representación social. In R. García-Mira, J. M. S. Cameselle, \& J. R. Martinez (Orgs.), Psicologia y medio ambiente: aspectos psicosociales, educativos y metodológicos (pp. 133-147). Espanha: Universidade de
Santiago de Compostela.

Wagner, W. (1998). Sócio-gênese e características das representações sociais. In A. S. P. Moreira, \& D. C. Oliveira (Orgs.), Estudos interdisciplinares de representação social (pp. 3-25). Goiânia: AB.

Gislei Mocelin Polli, mestre em Psicologia pela Universidade Federal de Santa Catarina, é doutoranda na mesma universidade. Endereço para correspondência: Rua Doutor Abel Capela, 995, Bloco 3/101, Coqueiros, Florianópolis-SC. CEP.: 88080-251. E-mail: gismocelin@gmail.com

Ariane Kuhnen, doutora em Ciências Humanas pela Universidade Federal de Santa Catarina, é professora do Departamento de Psicologia da mesma universidade. E-mail: arianekuhnen@gmail.com 